REVISTA IBEROAMERICANA. Vol. LXII, Núm. 174, Enero-Marzo 1996; 149-161

\title{
EL CUERPO MASCULINO VISTO POR OJOS LATINOAMERICANOS: SANTA MATERIA (1954) DE BENJAMÍN SUBERCASEAUX Y "VIDA EJEMPLAR DEL ESCLAVO Y EL SEÑOR” (1983) DE MANUEL RAMOS OTERO
}

\author{
POR \\ Ramón García Castro \\ Haverford College
}

En este ensayo vamos a seguir las sugerencias de Sylvia Molloy en "Too Wilde for Comfort: Desire and Ideology in Fin-de-Siècle Spanish America", donde explica que el temor a la homosexualidad ha impedido la presentación del cuerpo masculino tanto en la literatura hispanoamericana como en la crítica:

One of the results of turn-of-the-century homosexual panic has been the near-total supression of the male body from Latin American literature: the sentimentalized virility of Rodó is above all a cosa mentale, an abstraction never accompanied (as were similar national movements elsewhere) by the rediscovery and aesthetization of the body. And, as the body is hidden, so have all sexual and erotic manifestations deviating from "healthy", patriarchal, heterosexual norm successfully remained in the closet of literary representation and, especially, in the closet of literary criticism. One of the tasks that await the critic is to look... in order to figure out the forms taken by silence, the oblique figurations to which it has resorted to speak the unspeakable. ${ }^{1}$

Aquí vamos a ver cómo muestra el cuerpo masculino el chileno Benjamín Subercaseaux para contrastarlo con la presentación que hace por su parte el puertorriqueño Manuel Ramos Otero. Entre las fechas de publicación de Santa materia (1954) de Subercaseaux y "Vida ejemplar del esclavo y el señor" (1983) de Ramos Otero median casi treinta años llenos de acontecimientos en favor de una actitud más liberada hacia la cultura gay: la década de los sesenta - tan revolucionaria de la sexualidad en general- más el cambio hacia la aceptación de la homosexualidad en los países protestantes de Europa y, a partir de Stonewall en 1969, en los Estados Unidos. Dos generaciones diferentes; distintos estilos, por lo tanto. Subercaseaux se va a basar en una tradición científica que viene de Carl von Linneo "estudiar y categorizar a las razas humanas" para mostrarlas en un ensayo y tratar de ocultar su homosexualidad en ese intento. Ramos Otero será el polo opuesto; mediante un discurso homoerótico feroz, señalará en su cuento la violencia que todavía "según él" subyace en las relaciones homosexuales.

\footnotetext{
' Sylvia Molloy, "Too Wilde for Comfort: Desire and Ideology in Fin-de-Siècle Spanish America", Social Text 31-32 (1992) 199.
} 
Otra diferencia fundamental es que Subercaseaux viene de una tradición europea estudió psicología en La Sorbona y vivió un tiempo en París; por su parte Ramos Otero muestra la influencia de la liberación homosexual norteamericana porque pasó la década de los setenta y de los ochenta en Nueva York.

Benjamín Subercaseaux Zañartu (1902-1972), escritor chileno de ensayos, novelas y poemas, se atrevió a hablar de lo que no se habla en Santa materia (1954), un ensayo de su madurez, que se publicó cuando tenía 52 años. Debido a la dificultad de la tarea, lo hizo eso sí tomando muchísimas precauciones; entre ellas la tradición científica que le sirve para ocultar su deseo de hablar de los hombres como objetos sexuales. Son - tretas del débilcomo diría Josefina Ludmer. ${ }^{2}$ Su estudio se basa en el hombre inglés, francés, italiano, árabe, negro y chileno. Este ensayo está engarzado en un texto más amplio y muy imaginativo, donde se habla de la materia virgen (las piedras, la tierra, el agua), la materia viva (lo vegetal, las flores, las raíces, el césped, las algas), la materia animada (el elefante, el gato, los perros, los simios), y de la materia intencionada (hombres y mujeres, las razas, la mano, el pie, el torso), denominándolas santas por ser creación divina. Así justifica, por lo tanto, que se le preste atención a toda la materia, sin excluir el cuerpo del hombre, tan poco descrito en la cultura patriarcal de Occidente. hombre:

John Boswell menciona que hay dos tipos de cultura con relación a la belleza del

At one extreme, beauty is conceived as a male attribute: standards and ideals of beauty are predicated on the male model, art emphasizes male beauty, and males take pride in their own physical attractions. Greece and the Muslim world approach this extreme. ${ }^{3}$

This pole can be contrasted with societies in which "maleness" and beauty are thought unrelated or even contradictory, and beauty is generally predicated only of females. In such societies "maleness" is generally idealized in terms of social roles, as comprising, for example, forcefulness, strength, the exercise of power, aggression, etc. In the latter type of society, which the modern West approaches, "beauty" would generally seem inappropriate, perhaps even embarrassing by males, and males possessing it would be regarded as "effeminate" or sexually suspect to some degree (31).

Subercaseaux escribe un ensayo que va por el lado de los griegos y musulmanes, en vez de seguir la pista occidental moderna, y de ahí la extraordinaria tendencia a justificar su obra, incluso desde el punto de vista moral:

Celoso de evitar un daño, y en el convencimiento de estar realizando obra positiva y no negativa, el autor se ha posado nuevamente la pregunta en este último "Libro".

2 Josefina Ludmer, "Tretas del débil" en La sartén por el mango: encuentro de escritoras latinoamericanas, edición de Patricia Elena González y Eliana Ortega (Río Piedras: Ediciones Huracán, 1984) 47-54.

3 John Boswell, "Revolutions, Universals, and Sexual Categories" en Hidden From History, Reclaiming The Gay and Lesbian Past, ed. Martin Bauml Duberman, Martha Vicinus y George Chauncy, Jr. (Nueva York: New American Library, 1989) 30-31. 
Pues bien, he llegado al convencimiento íntimo, y también exterior y científico, de que no hay en este intento ningún peligro para el lector normal, sea cual fuere su edad ... Ahora, si este "Libro de la Materia Intencionada" y lo que en él se explica, crea un exceso de videncia ... y si este exceso pudiera incitar la malicia o el instinto en un sentido no deseable, me atrevo a afirmar rotundamente que este tipo de conocimientos "enferma" solamente a los que ya estaban "enfermos", a los que sintonizaron porque ya poseían un dial que incluía previamente esta sintonía. ${ }^{4}$

La soledad que se advierte en Subercaseaux resulta dolorosa; su intento en otro tipo de cultura como la griega antigua o la musulmana no le procuraría tanta precaución, ni tanto temor de estar haciendo algo malo. De ahí el deseo de pureza que se vislumbra en el epígrafe: "A los espíritus religiosos/este manual de piedad/ sui generis", y realmente lo es porque abarca muchas materias, desde la arena al caballo, y desde el inglés a los lunares. Pero en él, a pesar de todo, predomina el deseo de contar, de narrar lo observado, de confesar su capacidad de ver de manera diferente de los demás. Y en esto Subercaseaux sigue la tendencia occidental, que Michel Foucault analiza, de hablar del sexo a la vez que la represión aumenta a partir de siglo XVII:

Yet when one looks back over these last three centuries with their continual transformations, things appear in a very different light around and apropos of sex, one sees a veritable discursive explosion. ${ }^{5}$

Así, por lo tanto, represión y confesión van unidas, lo que resulta contradictorio, si se quiere. De ahí que describir el cuerpo masculino sea tan inaudito en el medio chileno que por lo tanto Subercaseaux lo justifica diciendo que las mujeres no ven la belleza del hombre, están incapacitadas para hacerlo porque su naturaleza no lo requiere, por ser la mujer el elemento de base, de estabilidad ${ }^{6}$ — ¡hoy en día un juicio muy debatible, por cierto!

Por otra parte el hombre se hace como que no advierte la belleza de sus congéneres porque no es de hombre confesar que otro es bello — según el escritor, en Chile se lo reemplaza con la palabra "simpático"- aunque el hombre sí capta el atractivo de los otros mejor que las mujeres (240).

Además Subercaseaux agrega que no es de homosexual tampoco esta capacidad de admirar lo masculino porque los homosexuales feminoides, como las mujeres, no ven asimismo al hombre (242).

En el fondo lo que Benjamín Subercaseaux no quiere es que se lo acuse a él mismo de homosexual. A menudo usa "normal" (290) por el heterosexual, desligándose siempre de que lo puedan incluir en el grupo "anormal" - producto solamente de la represión homofóbica.

El capítulo del cuerpo masculino es muy corto y se titula "las razas". En esta galería internacional de tipos humanos, la más notable de las seis descripciones es la extraordinaria

\footnotetext{
${ }^{4}$ Benjamin Subercaseaux, Santa materia (Santiago: Zig-Zag, 1954) 244-5.

${ }^{5}$ Michel Foucault, The History of Sexuality I. Trad. Robert Hurley (Nueva York: Pantheon Books, 1978) 17.

${ }^{6}$ Subercaseaux 238-240.
} 
apología del negro "o el sexo propiamente humano". Aquí Subercaseaux contradice lo dicho por Carl von Linneo (1707-1778) porque éste muestra una clara preferencia por la raza blanca. ${ }^{7}$ Resulta interesante que destaque a la raza más victimizada por los europeos con la esclavitud, tal vez porque coincide en este papel de ser despreciado, rechazado, con el del homosexual en nuestra cultura. Además on dit en Chile que la familia Subercaseaux tiene antepasados negros por provenir del Caribe, lo que indicaría su deseo de adelantar a su propia estirpe, mostrándola como la mejor entre las otras. Subercaseaux, citando a estudiosos de su época, dice que todas las características del negro -esqueleto, piel, labios abultados, pelo, tipo de sexo en el hombre, nalgas, falta de pilosidad, abundancia de glándulas sebáceas y sudoríficas, color de ojos, etc., todo indica que son los seres humanos más alejados del simio; según el escritor son exactamente lo que la biología quería hacer del hombre y lo logró en el negro, no en el blanco tan similar en todo al animal (287), al mono. Agrega además una característica que calza con la intención defensiva de Subercaseaux, que "el negro representa al hombre integral y al sexo normal; y es por eso que no existen entre ellos las perversiones y que es muy rara la homosexualidad, que tanto abunda, en cambio, entre los pueblos semitas y los aborígenes de América” (290). ¡Es obvio, por lo tanto, que el sexo normal para el escritor excluye la homosexualidad!

Dos razas no resultan muy bien paradas: el sajón o "el sexo de la necesidad higiénica" y el italiano, o "el sexo de la posesión". El sajón "promete mucho y entrega poco" (272) porque tiene escaso tejido conjuntivo y se le ven los músculos al aire y le queda mucho esqueleto a la vista. A veces es "de gran colorido"(272), pero en general "el cuerpo del sajón corresponde - sensualmente- al del caballo" (270). Eso sí, tiene brazos bonitos y una mano abarcadora. Se puede decir que es "una raza hermosa solamente en la infancia y en la adolescencia" (272), pero Subercaseaux recalca las malas tendencias de este grupo humano - se entrega "a la violencia de la orgía, del alcohol" (272) en un país "donde la sensualidad se concentra necesariamente, para desgracia suya y de su 'moral', en torno a los y las menores de edad" (272).

Como se puede ver, la crítica es fuerte - alcoholismo, orgías, pederastia, gente poco atractiva.

El italiano no queda mejor - peludo, de espalda gibada, con los músculos como los sajones, lleno de venas, con los órganos genitales colocados casi entre las piernas, con los

${ }^{7}$ Linneo clasificó a las razas humanas en "Systema natural per regna tria naturae". Esto es lo que dice del blanco y del negro en el volumen I de 1789:

European
White, ruddy, muscular.

Abundant yellow hair; blue-eyed.

Light, active, ingenious.

Covered with tailored clothes.

Governed by customs.

Black, phlegmatic, indulgent.

Hair black, kinky, skin smooth, flat nose, tumid lips.

The woman with a natural apron, the breasts lactating abundantly.

Crafty, lazy, negligent.

Anoints himself with oil.

Governed by whim.

Walter Sheidt, "The Concept of Race in Anthropology and the Divisions into Human Races from Linneus to Deniker" en This is Race, ed. Earl W. Count (Nueva York: Henry Schuman, 1950) 356. 
testículos pendientes a diversas alturas, "como lo requieren los tratados de anatomía, que, en este aspecto, parecen haber sido escritos por italianos ..." (277).

Además es impetuoso con la mujer, quiere poseerla como una propiedad y ella acepta este tipo de relación. La máxima sorpresa para Subercaseaux es que los escultores italianos hayan hecho obras tan importantes con los modelos que han tenido: " $¡ V$ Verdaderamente han sido grandes los escultores italianos si lograron crear arte con tales modelos!" (277). El lugar común es que el italiano es muy atractivo, pero obviamente no para Subercaseaux, al que le gusta no poco ser iconoclasta.

Los otros tres tipos de cuerpo "el del francés de origen galo, el del árabe y el del chileno de pueblo" aparecen descritos de manera más íntima, como si el autor los conociera más de cerca. Así, del francés, "o el sexo de lo sucio-hermoso", el escritor recalca la sexualidad olfativa de este grupo "más apetitoso que hermoso" (273). "Es un sexo que busca los perfumes corporales, lo oculto y procaz en cierta medida, en una suerte de delirio perruno y olfateante" (274). Una ventaja de los franceses es que es el grupo que más reacciona a los otros - “han llegado seguramente a la más perfecta captación del mensaje de la Materia Intencionada, sin apartarse del rasgo humano, del respeto sentimental y de la delicadeza afectiva" (275). También a su favor está el hecho de que no juega un papel tradicional en el amor - "En el sexo francés, todo parece fundirse en una misma esencia gozosa, sin atender para nada a los papeles tradicionales que le corresponda representar a cada partenaire, apuntando solamente al concepto de lo 'fraternal'. De ahí, quizás, que el hombre francés sea juzgado -injustamente, a mi modo de ver- como un hombre afeminado" (275). Otra defensa de su familia, francesa en este caso, como se puede ver.

Según el escritor, el francés es un homme à femme -que es lo contrario- lo que no excluye que, como el francés es el ser más abierto a la sexualidad, bien pueda caer en experiencias homosexuales (275). Como hemos dicho, Subercaseaux estudió psicología en La Sorbona, lo que tal vez explique esta gran familiaridad con el hombre galo.

En el árabe, "o la ternura de la posesión", el ensayista describe de manera muy íntima a los habitantes de Tunisia, Argelia y Marruecos, siguiendo en parte la tradición orientalista francesa en que el occidental ve el mundo musulmán como un espectáculo excéntrico. " árabe es un ser humano como los demás, y nada despreciable" (279). "Es la raza poseedora de los más bellos ojos que yo haya contemplado jamás" (279), pero el escritor se queja "de la presencia del traje talar, que los occidentales estamos acostumbrados a ver sólo en la hembra" (279). Por suerte, eso sí, hay baños donde se puede llegar a conocer el cuerpo del árabe. Luego pasa a explicar que "las partes sexuales son bastante desarrolladas, y en su dibujo, armónicas, a pesar —o debido—de la mutilación ritual del prepucio, que según ellos favorece su crecimiento" (280).

El árabe es una "herramienta perforadora" de mujeres y de hombres porque "—como todos los orientales - su libido es un tanto indeterminada" (280). Según Subercaseaux, el árabe, si bien activo en el amor, es pasivo en las caricias tal como el chileno del que vamos a hablar más tarde. "En el árabe, la posesión no es un derecho avasallador, y menos ultrajante" (280). Hay gran delicadeza y sincero afecto, una ternura casi paternal, "de muy buena calidad moral y hermosamente consciente de su responsabilidad" (280).

${ }^{8}$ Edward W. Said, Orientalism (Nueva York: Vintage Books, 1978) 102-3. 
Un comentario que muestra la cercanía del escritor con el árabe es el que explica que "la piel del árabe no es muy suave, sin ser necesariamente áspera" (280). Si bien en Subercaseaux predomina la observación lejana, también se pueden advertir comentarios como éste que nos dicen que igualmente ha habido cercanía con estas razas descritas con tanto detalle.

Es de notar en esta misma tendencia su descripción del ardor de la piel de árabe que es "como un llamado perpetuo y angustioso a compartir su placer" (281) "con el fuego de una pasión vehemente, pero a la vez tiernamente garantizadora de su propia sinceridad" (281).

Y finalmente "llegamos al más extraño ejemplar humano que haya salido de las manos de Dios o del demonio" (281).

El chileno, "o el sexo-delito", cierra esta presentación de cuerpos masculinos. Ya al hablar del francés, Subercaseaux se limita al grupo galo, rubio, dejando de lado el tipo mediterráneo de ese país, que no le agrada. Ahora, al hablar del chileno, selecciona al hombre de pueblo, "que es, racialmente, el único 'chileno' de verdad" (281).

Roberto Castillo Sandoval ha estudiado cómo cambia la actitud ambivalente hacia el araucano que se da desde la Conquista y en especial a partir de La Araucana de Alonso de Ercilla y Zúniga. Después de la Guerra del Pacífico, 1879-1884, y la Pacificación de la Araucanía, 1881-1883, este interés y rechazo tradicional se traslada hacia el hombre de pueblo, el "roto" chileno, al que se lo admira por su valor, por su resistencia, pero disgusta su embriaguez, tendencia al robo y afición a las riñas, como enumera Eduardo Solar Correa. ${ }^{9}$

Esta misma dicotomía se advierte en la apreciación de Subercaseaux, cuyo punto de vista es el de la clase alta de Chile. El chileno vestido se ve insignificante, pero desnudo "se presenta en forma no sólo aceptable, sino extraordinariamente atrayente". ${ }^{10}$ De la cintura para abajo es fuerte, con bellos muslos y tobillo grueso; de la cintura para arriba es fino y su cuerpo "se extiende en sentido lateral" (281), lo que le da un aire "de fuerza y finura" (282). "Su vientre es cóncavo y terso, de una línea purísma y tierna. El pecho, relievado (sobre todo en el araucano)" (282), descripción que se asemeja a la que hace Ercilla de Caupolicán en La Araucana: "de cuerpo grande y relevado pecho"."1

Los genitales aparecen descritos como "un hermoso contorno en el pueblo chileno, colocados muy por delante, como en los niños y provistos de un paquete esférico y recogido, lampiño y de gran suavidad. Un sexo que no haría necesaria la 'hoja de vid' al ser llevado a la escultura, porque no resulta indecente" ... "observación quizás chocante para muchos" ... pero que "no tiene la virtud de preocuparme en exceso". ${ }^{2}$

La parte "delito" se halla en la dificultad que muestra el chileno para establecer una relación erótica. Éste, según el escritor, niega la mirada, "se hace el leso", como se dice en Chile, y de golpe mira con toda intención. Subercaseaux continúa subrayando el elemento

${ }^{9}$ Citado por Roberto Castillo Sandoval en obra por publicar.

${ }^{10}$ Subercaseaux 281.

1 Alonso de Ercilla y Zuñiga, La Araucana, ed. Marcos A. Morínigo e Isaías Lerner, (Madrid: Clásicos Castalia, 1983), Canto II, estrofa 47, verso 5.

${ }^{12}$ Subercaseaux 283. 
infantil del chileno (ya lo hizo al hablar de los genitales) cuando recuerda a Freud y su "presexualidad infantil, cuando el niño retiene voluntariamente las heces, para retardar y prolongar así el placer de la evacuación" (283), relacionándolo con esta contención sexual del hombre de pueblo. Asimismo, durante el sexo, muestra una "prescindencia aparente de su "yo"" (284), en un placer de tipo "solitario en su esencia" (284), "masturbatorio" (275) y femenino por ser una actitud "inapetente de lo que posee e incomprensiva de lo que se le ofrece" (274), porque ama lo prohibido, "lo que produce dolor, desafecto, humillación, deslealtad y hasta fealdad" (284). Esta actitud produce "el más prometedor de los mensajes, interferido por el propósito menos satisfactorio" (284), que hace que este pueblo, a pesar de que su "temperamento sexual es débil" (284), "viva y muera por el sexo y para el sexo, en una obsesión morbosa y excesiva para el correcto funcionamiento de sus potencias mentales, morales y viriles" (284-85).

Es notable cómo Subercaseaux presenta al chileno como el caso tal vez más complejo de todos los demás, en un trozo lleno de atracción, pero de imposibilidad de apretar, de dominar, de lograr una respuesta profunda de este cuerpo tan atrayente. Los adjetivos "satánico" y "endiablado" aparecen por primera vez en este texto junto con la crítica y la admiración, con un chileno al que se lo describe en términos de hombre, de mujer y de niño de manera muy compleja por lo tanto - por ser un individuo producto de Dios o del demonio- debido a la rareza, a la insatisfacción que provoca. Es obvio que el cuerpo del chileno es el que más resonancia tiene en Subercaseaux y es tal vez el que mejor conoce si es que se lo puede conocer jamás.

Es curioso, además, que mencione al chileno cuando está hablando del árabe (274-75) porque parecería ser que también estuviera entroncando a su connacional en la tradición orientalista, de ser excéntrico, de una cultura diferente a la suya. Este hecho se refuerza cuando el ensayista usa los adjetivos "satánico" y "endiablado" para describir al chileno, los que aparecen igualmente en dicha tradición como lo ha visto Israel Burshatin. ${ }^{13}$

Pero "las razas" no es lo único que aparece en "El libro de la materia intencionada". Hay además capítulos sobre la piel y el pelambre, sobre la mano, el pie, el pecho, la nuca, el torso, la mirada, la boca, los lunares, el perfume humano, la voz y el aura de una persona. No nos referiremos a ellos porque hemos querido concentrarnos principalmente en el cuerpo total.

Fernando Alegría dice que Santa materia es la "expresión máxima de su esfuerzo por acercarse a una caracterización del pueblo chileno a base de observaciones científicas que, moldeadas por su rara sensibilidad, adquieren el sentido de certeras imágenes estéticas". ${ }^{14}$

"En trabajos literarios como Tierra de océano o Santa materia, el cultivado artista no sólo provoca un verdadero asombro por la vastedad de sus conocimientos de diversas disciplinas científicas, sino que transmite al lector el fruto de sus profundas observaciones sobre los temas estudiados, mediante formas de expresión que se amoldan con ductilidad

\footnotetext{
${ }^{13}$ Israel Burshatin, "The Moor in the Text: Metaphor, Emblem and Silence," en "Race", Writing, and Difference, ed. Henry Lous Gates, Jr. (Chicago-Londres: University of Chicago Press, 1986) 136-37.

${ }^{14}$ Fernando Alegría, La literatura chilena del siglo XX (Santiago: Zig-Zag, 1962) 125.
} 
a las complejas ideas presentadas en tales obras", ${ }^{15}$ agregan Magdalena Correa Larraín y Eduardo Cruz-Coke Madrid.

Dos juicios positivos (pero que desconocen toda la carga sexual que encierran estas descripciones masculinas) dentro del silencio que hay alrededor de Santa materia. Este callar lo ejemplifica perfectamente Arturo Tienken que en un reciente ensayo ${ }^{16}$ suyo habla de muchas obras de Subercaseaux tanto como de su personalidad, pero no menciona Santa materia “¿demasiado desagradable el tema?, ¿ensucia este ensayo la memoria de Benjamín Subercaseaux Zañartu? o ¿es sencillamente que Tienken, no lo ha leído? ...

En resumen: el cuerpo en Subercaseaux forma parte de la materia que es santa, lo que suaviza el atrevimiento del escritor al describirlo en su desnudez y en su actividad erótica. Algunas descripciones parecen ser solamente eso - relatos de lejos-como en el caso del inglés y del italiano; otras son apologías raciales como la del negro, y en las restantes se advierte menos distancia porque las experiencias sexuales se describen con gran conocimiento de causa, destacándose el endiablado chileno de pueblo que atrae y rechaza sin entregarse jamás, aunque consienta a hacer el amor. Hay que destacar que, aunque Subercaseaux trata de disimular lo más posible, resulta impensable imaginar que se haya atrevido a publicar Santa materia en Chile en 1954 porque incluso ahora, debido a la homofobia prevalente, todavía resultaría muy controversial e incluso, risible.

De Manuel Ramos Otero (1948-1990) cabe destacar que nació y murió en Puerto Rico, pero vivió la mayor parte de su vida adulta en Nueva York. Escribió prosa (cuentos, novela) y poesía. Lamentablemente murió muy joven de SIDA, como muchos otros en estos tiempos.

Su cuento "Vida ejemplar del esclavo y el señor" $(1983){ }^{17}$ muestra el cuerpo masculino en tres espacios:

1) En una novela pornográfica con una pareja gay en acción erótica sadomasoquista.

2) En el lector de esta novela que en un mediodía neoyorkino se masturba encerrado en su departamento con celosías rosadas, escuchando la "Polonesa Militar Opus 40, número 1 " de Chopin.

3) En la realidad homofóbica de Puerto Rico, que le llega, o que el personaje que lee inventa después de una llamada telefónica poco clara que interrumpe por un momento su actividad masturbatoria.

El cuerpo masculino en la novela pornográfica es puro llamado a la acción. La pareja del esclavo y el señor aparece enfocada principalmente en el esclavo que, como si fuera señor, le ordena a su compañero con imperativos que se tienen que obedecer: "hazlo como te digo o no lo hagas, escúpeme la cara", 18 "hazlo más duro o no lo hagas" (41); "oríname

\footnotetext{
${ }^{15}$ Magdalena Correa Larraín y Eduardo Cruz-Coke Madrid, Grandes escritores chilenos (Santiago: Editorial Andrés Bello, 1989) 76.

${ }^{16}$ Arturo Tienken, "Chile en la obra de Benjamín Subercaseaux" en Literatura chilena: creación y crítica (Hollywood, CA [Lit C] 1987) 6-10.

${ }^{17}$ Le agradezco a Dorian Lugo la paciente discusión y las ideas tan acertadas sobre este cuento, pero es de mi sola responsabilidad lo escrito.

${ }^{18}$ Manuel Ramos Otero, "Vida ejemplar del esclavo y el señor" en Apalabramiento: Diez cuentistas puertorriqueños de hoy, ed. Efraín Barradas (Hanover NH: Ediciones del Norte, 1983) 41.
} 
la vida o no me orines" (42); "méteme el puño entero o no me lo metas" (43); "mámame como te digo o no me mames" (45).

Jeffrey Weeks expresa que el sadomasoquismo se ubica en el punto extremo de la sexualidad aceptable, ${ }^{19}$ pero que "sado-masochism becomes a theatre of sex, where the consenting partners freely engage in extreme activities ... to attain an intensified sense of release and pleasure" (237). Este reflejo de la situación de poder que se da en la realidad de todos los días, se vuelve juego en el que se establece una relación satisfactoria para la pareja que conoce los límites de la dureza de la acción. Y de ahí la ejemplaridad de este discurso pornográfico: estos dos hombres se entienden porque como aparece en el texto, "soy el esclavo del señor, soy el señor del esclavo". ${ }^{20}$

El cuerpo masculino se ve mostrado en su totalidad amatoria de la cabeza a los pies, con un lenguaje violentamente erótico. Aquí no se advierten tapujos. Ramos Otero usa tal vez uno de los discursos más fuertes de la literatura hispanoamericana, doblemente efectivo y chocante por tratarse de una relación homosexual.

La realidad externa - ya sea verdadera o imaginada por el personaje onanista - que interrumpe con una llamada telefónica la lectura de la novela pornográfica, también aparece retratada con una brutalidad extrema. El homosexual pasivo -_“¿cuántos charcos de leche le encontraron adentro?" (45)- asesinado sufre una muerte casi tan grotesca como la de Palomino Molero en ¿Quién mató a Palomino Molero? de Mario Vargas Llosa. Por ser lo que es, este hombre ha muerto de un tiro de pistola "en la garganta más profunda" (45); "le rompieron una botella de Coca-Cola en el culo" (45) y "después le cortaron el bicho con la navaja de barbero y se lo metieron en la boca para que siguiera mamando en el masallá" (45). Lo dejan castrado, "en el cañaveral donde quemaron a Correa Cotto" (45), sin ni siquiera cerrarle los ojos (46).

Resulta obvio que la realidad es muchísimo más violenta que los juegos eróticos de la pareja pornográfica. Aquí el homosexual pasivo no puede ser "señor" aunque así se lo nombre (45) en el relato; es sólo víctima con mutilaciones terribles exclusivamente por su preferencia sexual pasiva tan indeseada. El homosexual pasivo provoca una reacción adversa en muchas culturas, incluso en las que la homosexualidad es aceptada. Hasta el momento, por lo tanto, el relato se centra en la pasividad sexual más que en su parte activa, ya sea esta última representada por el bujarrón o por otro homosexual como el "señor" de la novela pornográfica. Este poder del pasivo se advierte especialmente en el esclavo de la novela pornográfica porque no eyacula y sí, abundantísimamente, el señor. ${ }^{21}$ Según Frank Browning, la carencia de eyaculación del homosexual pasivo es una forma de dominar al activo porque éste resulta exhausto después de hacerlo y se lo puede reemplazar inmediatamente por otro:

\footnotetext{
${ }^{19}$ Jeffrey Weeks, Sexuality and Its Discontents (Londres, Melbourne y Henley: Routledge and Kegan Paul, 1985) 236-67.

${ }^{20}$ Ramos Otero 45.

${ }^{21}$ Arnaldo Cruz-Malavé también ve al esclavo como figura dominante en este cuento en "Para virar al macho: la autobiografia como subversión en la cuentística de Manuel Ramos Otero", Revista Iberoamericana LIX, 162-163 (enero-junio, 1993) 250. En la cita 2, Cruz-Malavé da una lista muy nutrida de las obras de Ramos Otero.
} 
And that is just what happens when the hairy, muscled man spreads his buttocks and releases himself to penetration by another. He has ostensibly relinquished control over the course of his own pleasure to the man who is entering him. But because his pleasure is not directed toward orgasm, he is in his "powerless" submission capable of outlasting, and forgetting, his top man, who, upon orgasm, can be replaced again. ${ }^{22}$

Para finalizar con el pasivo en "Vida ejemplar del esclavo y el señor", la muerte del "señor" en Puerto Rico es también ejemplar: es un retrato vivo de la realidad homofóbica de su tierra y de las otras culturas patriarcales del mundo.

Por otra parte - volviendo a la obra de Subercaseaux - resulta interesante que el chileno de clase baja, de menos poder por lo tanto, en la relación sexual supuestamente con el autor de clase alta, muestra una actitud "inapetente de lo que posee", ${ }^{23}$ poderoso en su desdén, "e incompresiva de lo que se le ofrece" (274), separado, "solitario en su esencia" (284) -lo que sugiere también un dominio y control de la situación por parte del "esclavo" sobre el "señor", repitiendo así el esquema del cuento de Ramos Otero- un punto de contacto entre los dos autores, por lo tanto.

El tercer espacio lo ocupa un homosexual encerrado en su cuarto, separado del mundo, que lee el discurso pornográfico y que reacciona frente al llamado de larga distancia que interrumpe su lectura. De su cuerpo en ese momento sabemos muy poco: que no logra tener una erección sino hasta que el señor de la novela le mete el puño al esclavo. ${ }^{24} \mathrm{Su}$ cuerpo aparece en su recuerdo cuando anda buscando un esclavo por las calles del Village en Nueva York: mahones rotos, sin ropa interior (42), "lienzos sucios", "tenis blancos gastados de tanto caminar por ahí esperando que pase su esclavo" (43), peste en los pies (43). No parece ser un "señor" muy exitoso porque se queda solitario, fuera del juego callejero y no logra atraer a ningún hombre. Así él mismo lo reconoce: "Huele a culo mirado pero no tocado" en la noche mientras se "recuesta contra el filo perpendicularmente perfecto de un edificio" (43). De ahí que lea novelas pornográficas y se masturbe de día, alejado de su objetivo erótico, solo y sin compañero.

La violencia también se presenta en este espacio cerrado; después de la interrupción telefónica, rodeado de "la correa de cuero oloroso", del "látigo de puntas de metal las sogas inmóviles la navaja amolada en piedra carne y el smith-wesson 32, tuvo que hacerse la puñeta reguindado a los barrotes" (45), arrasando, desconstruyendo todo lo que lo rodea con su eyaculación tan excesiva como la del señor de la novela pornográfica y tan destructiva como la que recibió en la realidad el "señor" en Puerto Rico: "pero llegaba la leche hasta el teléfono después de haber inundado la habitación y las persianas de color rosa, el disco de la Polonesa Militar y la radiola, el abanico de aspas y la sirena de la policía, los uniformes azul añil y las macanas, los ojos abiertos del cadáver, la novela (Vida ejemplar del esclavo y el señor) y la nada" (45-46).

Si bien sólo a veces en este relato se evitan las comas y todo fluye rápido, en general lo que predomina es la interrupción tal como en La guaracha del Macho Camacho de Luis

\footnotetext{
${ }^{22}$ Frank Browning, The Culture of Desire (New York: Crown Publishers, Inc., 1993 ) 90-91.

${ }^{23}$ Subercaseaux 274.

${ }^{24}$ Ramos Otero 44.
} 
Rafael Sánchez. En la novela de este último eso sí el objetivo es mostrar cómo Puerto Rico está en un tapón total, detenido por su situación política principalmente. En Ramos Otero la interrupción se refiere a la violencia que sufre el homosexual y que se refleja en todos los aspectos de su vida, pero en especial cuando manifiesta su sexualidad. El parecido entre los dos autores puertorriqueños es notable, eso sí. Basta ver, por ejemplo, en la novela de Sánchez el "cerebro" que hace la Corteja con sus primos macharranes cuando espera al Senador, y un trozo de la novela pornográfica Vida ejemplar del esclavo y el señor, de Ramos Otero, para advertir un asombroso parecido:

Secuencia del macharrán mayor en escala everéstica de la autora del cerebro. Corte. Tomas intermitentes del humor llamado sudor brotando a chorros por los poros de la pareja. Corte. Plano primerísimo de un poro sudado. Corte. Plano primerísimo de un poro sudando. Corte, ${ }^{25}$

y en Ramos Otero:

hazlo como te digo o no lo hagas. escúpeme la cara. baja baja la saliva baja baja ... escupe mientras la mano tiesa. escupe como te digo o no me escupas. sobre los ojos para no ver. ${ }^{26}$

La interrupción en Ramos Otero puede deberse a la lectura vacilante del personaje onanista o bien puede deberse a la violencia de la acción en la pareja pornográfica. La interrupción se repite con el llamado telefónico, que termina con el orgasmo del lector solitario que interrumpe brutalmente la lectura tanto como la noticia del asesinato, al imponerse él mismo como un "señor" imperioso de una masturbación solitaria, que barre con todo. Y ¿la "Polonesa Militar Opus 40, N¹" de Chopin? y ¿Las Rimas y leyendas de Gustavo Adolfo Bécquer que el onanista imagina que leen los presos de la cárcel la Princesa en el Viejo San Juan? (42-3). Si bien la "Polonesa Militar Opus 40, N¹" es muy optimista $\mathrm{y}$ de tono conquistador (que es la única que oye el lector en su departamento), en la realidad apareció publicada en 1839 con la $\mathrm{N}^{\circ} 2$, que es triste, de muerte y de derrota. Por otra parte resulta interesante constatar que el personaje lee una novela pornográfica, pero imagina a los presos leyendo al autor español más romántico del siglo XIX. ¿Un aspecto - lo romántico-que él suprime en su búsqueda de su "esclavo", o es que no puede o no se atreve a ser esclavo él mismo, que es lo que quiere ser probablemente en vez de un señor fallido? $¿ \mathrm{O}$ es que hay que entregarse totalmente a ser esclavo para ser totalmente señor - "soy el esclavo del señor, soy el señor del esclavo" (45) - como se da en los otros dos espacios del cuento, pero en especial en el de la novela pornográfica?

El relato termina en una coda — “además" (46)_ separada del resto del cuento, coda musical que conduce hacia un futuro que sólo el lector puede construir, tal como los finales de Sánchez con respecto a sus propios personajes en La guaracha del Macho Camacho con excepción del Nene. Como ejemplo de esta apertura final tenemos el de la Madre-Corteja

${ }^{25}$ Luis Rafael Sánchez, La guaracha del Macho Camacho (Buenos Aires: Ediciones de la flor, $3^{\mathrm{a}}$ edición de 1977) 141.

${ }^{26}$ Ramos Otero 41. 
en Sánchez: "Ella pensaba que te pensaba que te piensa: irme de artista con el nombre de La Langosta, y hacerme famossssa y dar opinionessss y firmar autógrafossss", ${ }^{27}$ planeando abandonar al Senador que, por el tapón, no se ha presentado esa tarde. El "además" de Ramos Otero le da igualmente alternativas al lector. ¿Es un "además" negativo, un "no me importa nada" de parte del onanista? ¿o se abre una posibilidad de cambio en el futuro? Con ese interrogante, Ramos Otero cierra un cuento denso y con estructura musical en su lenguaje. Además resulta ejemplar, haciendo eco de los exempla medievales españoles, en sus tres niveles - el de la novela pornográfica, el de la realidad asesina y en el nivel de este personaje en un tapón físico y emocional, tal como los de Sánchez en su Guaracha del Macho Camacho.

La novela pornográfica del esclavo y el señor se entronca en la obra del Marqués de Sade, pero, aunque el lenguaje es muy fuerte, no llega al exceso escatológico del francés. En Les cent vingt journées de Sodome el relato con el que la bella Duclos trata de estimular a los protagonistas en el día veintidós resulta más repugnante y con más humor a la vez que el de nuestra novela. Veremos el primer y el tercer relato de Sade.

La première fut celle d'un homme qui se faisait branler le cul avec un godemiché d'étain que l'on remplissait d'eau chaude, et que un lui seringuait dans le fondement à l'instant de son éjaculation, à laquelle il procédait de lui-même et sans qu'on le touchât ... ${ }^{28}$

Al tercero le hacen igualmente ponerse una enorme lavativa y procede a comerse el resultado de la acción: "il chiait, mangeait ce qu'il venait de rendre, et alors on le fouettait" (273).

Esta concentración en lo anal - entre otras, porque Sade erotiza todo el cuerpo humano- se repite en Salo: ciento veinte días de Sodoma de Pier Paolo Pasolini (1975), con resultados francamente asquerosos, pero aquí la intención del director italiano es criticar el fascismo de su patria, más bien.

Además, la fraternidad violenta del esclavo y el señor se repite igualmente en Jean Genet:

-Qu'est-ce qu'il y a? On saigne?

Il tenait toujours ses mains en avant, semblant les chauffer à des roses, mais il inspectait posèment les draps. Ma verge saignait. Je compris avant lui. Parce que j'y avais été dur, sans souci de ses plaintes j'avais écorché son cul, et ma queue, prise dans un cheveux ou un poil s'était coupée légèrement. Ainsi nous avions mélé notre sang. Il me dit:

-Tu as mal?

$\rightarrow$ Non c'est rien. Et toi? ${ }^{29}$

\footnotetext{
${ }^{27}$ Sánchez 207.

${ }^{28}$ Donatien Alphonse François Comte, llamado Marquis de Sade, Oeuvres Complètes, tome treizième (París: Editions Tête de Feuilles, 1973) 272.

${ }^{29}$ Jean Genet, Pompes Funèbres (Edicíon N 954 de 1.500, sin lugar de publicación ni editorial, 1948)

71-2. En las Obras completas de Gallimard no se encuentra este trozo.
} 
Por otra parte cabe recordar The Servant de Joseph Losey (1963), película en que el sirviente acaba por dominar al señor tal como en la novela pornográfica que lee el personaje de Ramos Otero. Con la supremacía del sirviente se advierte en esta película también un comentario social y político sobre la condición de Inglaterra en la década de los sesenta.

Para finalizar, el cuerpo masculino en Subercaseaux y en Ramos Otero es un instrumento de placer, pero no sin dificultades. En Subercaseaux su medio hace que el escritor describa desde lejos y lleno de explicaciones el cuerpo del hombre de seis razas, escondiéndose detrás de una máscara científica, pero dejando ver a veces en sus comentarios su conocimiento más íntimo de la materia que está tratando con tanto trabajo. En Ramos Otero, el personaje central no puede captar la lección de entrega de los personajes de la novela pornográfica porque todavía le teme a la postura pasiva, se queda pegado en una postura de señor avasallador que sólo lo lleva al alejamiento de una situación de convivencia con otro hombre.

Además, la misma violencia del lenguaje de la novela pornográfica que describe Ramos Otero acusa la represión homofóbica del mundo en que vive su autor, porque en su brutalidad, el escritor puertorriqueño parece tener la intención de épater le bourgeois, de espantar al público lector lanzándole a la cara una acción sadomasoquista fortísima, en vez de contar una relación entre dos hombres más bien por el lado de Chopin y de Bécquer, que aparecen incluidos en el relato. La represión homosexual, por lo tanto, matiza, carga el discurso de estos dos escritores, de alejamiento, de soledad, y, debido a la diferencia de generaciones, de violencia flagrante en el caso de Ramos Otero, pero afortunadamente no impide la confesión de la que habla Foucault. Esta se traduce a pesar de todo en discursos potentes y seminales para el lector que se tome el trabajo de leerlos.

Ya Sylvia Molloy ha acusado la represión en su artículo citado. Creo que esta acusación resulta muy válida y que el crítico la habrá de seguir teniendo en cuenta en el futuro, porque la represión sólo ha permitido expresarse a los escritores más valientes, dejando en el limbo muchas obras más que pudieran haber sido escritas de no haber existido dicha actitud tan negativa contra el homosexual. Resulta alentador, eso sí, ver que poco a poco se le está dando la guerra a esta violencia negativa, y que es de esperar que pronto resulte más fácil escribir en castellano sobre estos temas tan ocultos e inauditos, bien sea en obra creativa o en la crítica. 
